\title{
Outcome of Labor Induction and it's Associated Factor among Laboring Women at Dilchora Referral Hospital, Dire Dawa, Eastern Ethiopia
}

Abel Shiferaw ( $\nabla$ shifrawabel@gmail.com )

DireDawa regional health bureau

\section{Tesfaye Assebe}

Haramaya university

Melake Demena

Hararmaya university

Abeselom Assefa

Saint Paul's hospital millennium medical college

\section{Research Article}

Keywords: Induction of Labour, outcome, associated factor, Gestational age

Posted Date: June 24th, 2021

DOl: https://doi.org/10.21203/rs.3.rs-500130/v2

License: (c) (i) This work is licensed under a Creative Commons Attribution 4.0 International License. Read Full License 


\section{Abstract}

Background: Induction of labor has a great role to prevent neonatal and maternal mortality and morbidity. Despite its role Induction sometimes fails with a potential risk of increasing maternal and neonatal mortality and morbidity. In Dire Dawa, there was no study done on outcomes of labor inductions. Therefore, this study is planned to fill this gap by studying the outcome of labor induction and associated factors among women who had delivered at Dilchora referral hospital in Dire Dawa, East Ethiopia.

Objective: To determine the outcome of labor induction and associated factors among women who had delivered at Dilchora referral hospital Dire Dawa East Ethiopia, May 15 to June 1, 2020.

Methods: Hospital-based retrospective cross-sectional study (July 8, 2014 up to July 08, 2019) was employed by using a pre-tested structured questionnaire to collect data from a sample of 444 charts using a systematic random sampling method by trained data collectors. First, bi-variate analysis was done to select variables for multivariate analysis and those variables with p-value 0.25 or less interred into multivariate analysis. In multivariable analysis, those variables with p-value $<0.05$ are considered as significantly associated. The model adequacy was checked by using the Hosmer and Lemeshow goodness of fit test.

Result: The result of the study reveled Post-Term mother [(AOR: 0.49 (0.25-0.98. The mother whose labor is induced by misoprostol [(AOR: 2.5 (1.08-5.94] the mother whose labor is induced by both (oxytocin and misoprostol) [(AOR: $0.33(0.13-0.86)]$ and non-reassuring fetal heart rate pattern [(AOR: $0.10(0.03-0.30)$ ] were significantly associated with success of induction.

Conclusion: The prevalence rate of success of labor induction was found (83.6\%). And the most common indications for labor inductions were PROM and Post term. Furthermore, the study described that the most common method of induction in Dilchora referral Hospital is iv oxytocin and the minister of health should develop national evidence-based clinical practice guidelines for labour of induction and enforce its implementation.

\section{Introduction}

Induction of labor refers to the iatrogenic stimulation of uterine contractions before the onset of spontaneous labor to accomplish vaginal delivery(Cunningham et al., 2010). It is usually performed by administering oxytocin or prostaglandins to the pregnant woman, or by artificially rupturing the amniotic membranes(World health organization, 2018). and it indicated only when the risk of continuing the pregnancy to the mother and/or fetus exceeds the risk associated with the induced labor and birth (SOGC, 2008). Induction of Labor is not risk-free, and many women find it uncomfortable. the incidence of inducing labor Over the past several decades has continued to rise. In developed countries, the proportion of infants delivered at term following induction of labor can be as high as one in four births. In low- and middle-income countries the rates are generally lower, but in some low-income countries, they can be as high as those observed in high-income countries. (World health organization, 2018). 
An increased rate of induction of labor for post-term pregnancies over 15 years was associated with decreased stillbirth rates in Canada (Vogel et al., 2014). For a long period many health care providers has recommended the use of induction of labor in circumstances in which the benefit of continuing a pregnancy must be outweighed than the potential maternal and fetal risk associated with the procedure and waiting for the onset of spontaneous labor. These circumstances generally include gestational age of 41 completed weeks or more, pre-labor rupture of amniotic membranes, hypertensive disorders, maternal medical complications, fetal death, fetal growth restriction, chorioamnionitis, multiple pregnancies, vaginal bleeding, and other complications. Following this condition, many neonates and mothers die in each hour throughout the world to prevent maternal and neonatal death WHO design and implement a strategy in the area of improving and availing comprehensive emergency obstetric services. one of the strategies is the induction of labor(World health organization, 2018)

In Dire Dawa, there were un area with a high rate of maternal mortality and morbidity MMR calculated for the two periods (2013-2015) was 511 and 505 per 100,000 live births during baseline and trial periods, respectively (Tseyon, 2015). Those maternal mortality is due to poor access to comprehensive emergency obstetric care. Knowing labor outcome and associated factors following induction is crucial. In the investigator knowledge there is no study conduct in Dilchora referral hospital. Therefore, this study aimed to determine the outcomes of induction of labor and factors associated with induction of labor at Dilchora referral hospital.

Identifying magnitude and factors associated with labor induction outcomes will emphasize improvements in access to qualified care for laboring women that are necessary for a reduction in maternal life-threatening conditions. Since the labor induction outcomes, exploring and analyzing the severity of factors that provides important information for laboring women as well as for health care providers in setting priorities for in-depth assessments and health care improvements in maternal health. Furthermore, studies on labor induction outcomes related events in the study area are crucial to further understanding associated issues and to provide an evidence-based platform for appropriate interventions.

Since the study will explain factors associated with labor induction outcomes, study results will serve as an input for the health bureaus, health offices/departments, local NGOs and other stakeholders working in Dire Dawa city administration in planning and implementation of preventive and intervention strategies to improve maternal and neonatal health. Moreover, the study can also be used as a baseline framework for researchers for further studies that will be conducted in similar setups

\section{Materials And Methods}

\section{STUDY SETTING}

Hospital-based cross-sectional study was carried out From May 15 up to June 1, 2020 in Dilchora referral hospital. The hospital gives a referral service for different parts of the Oromiya and Somalia region. According to data from the hospitals labor ward registration book more than 400 inductions has been 
conducted in the 2018. The average monthly delivery service on Dilchora referral hospital in 2018 G.C is about 325 . So far, there have not been any properly documented studies to show induction of labor, its associated factor and labor outcome.

\section{POPULATION}

Source population was All women who had induction of labor and gave birth after 28 weeks of gestation in Dilchora referral hospital and the study population was All women who had induction and gave birth after 28 weeks of gestation in the Dilchora referral Hospital during the study period. All registered women who delivered through induction of labor after period of viability (28 weeks) were included in this study.

\section{SAMPLING SIZE AND SAMPLING TECHNIQUE}

The sample "size of outcome variable" for induction of labor is calculated using single population proportion formula considering the following assumptions: the level of confidence of $95 \%$, margin of error $4 \%$, proportion of success of labor induction from previous study to be $78 \%$,(Girma and Wolde, 2016). By adding $10 \%$ of the non-response rate the final sample size will be $404+40=444$. (Table 1 )

A systematic random sampling procedure was used to choose the study participants using delivery registration book $\mathrm{k}=$ Sampling interval from the first selected sample to the next to be selected in registration book, $\mathrm{N}=$ total population (1334), $\mathrm{n}=$ sample size(444). The sampling interval $(\mathrm{k})$ was calculated by dividing total population to sample size $(\mathrm{K}=3)$ So, the sample was picked every three charts from registration book. When there was missing chart for the selected sample, we picked the next. Lottery method was used to select the first sample from the first three.

\section{DATA COLLECTION AND PROCEDURE}

Data was collected by using a structured data-collecting checklist that was prepared and developed from previous studies Pretest of the questionnaire was done to $5 \%$ of the sample size to validate and customize the tool.Two midwifery professional, who are not working in the study sites was recruited as a Data collector and one integrated emergency obstetric surgeon as supervisors. Data collector was oriented to the data collection format by supervisor and principal investigator on daily basis P.I and supervisor was review all collected data and take corrective measures. Those midwifes Who would be trained as data collector was collect the data on the data collection tool and procedures under the supervision of one integrated emergency surgeon and the principal investigator For their completeness, accuracy and consistency. The data collector was start data collection after reviewing mothers chart for legibility. Those mother medical chart not fulfill the inclusion criteria will be replaced by next legible mother medical chart Based on the information obtained from the hospital delivery registration log books, and medical record a total of 444 patients card filled .

\section{OPERATIONAL DEFINITIONS}


Failed induction:- Failed induction is failure to initiate good uterine contraction. It is diagnosed if adequate uterine contractions are not achieved after 6 to 8 hours of induction (Federal Ministry of Health, 2010)

Outcome Of Labor Induction:- Proportion Of Success/Failure Of Induced Labor.

Success of labor induction:-if a woman delivered vaginally or by an instrument after induction with any of the methods.(Organization(WHO). 2011)

unsuccess of labor induction:- if a woman delivered by $\mathrm{C} / \mathrm{S}$ due to any indication for cs after starting of induction. (Organization(WHO). 2011)

Bishop score: A group of measurements made at internal examination, used to determine whether the cervix is favorable or not. The score is based on the station of presenting part, dilation, effacemccent (or length), position and consistency of the cervix. A score of 8 or more generally indicates that the cervix is ripe.(World health organization, 2018)

\section{DATA MANAGEMENT AND ANALYSIS}

To keep the quality of data, detail trainings given for data collectors. day to day activities during data collection; supervised and evaluated errors was corrected by the investigator before the following day activity. The checklist was pre- tested by taking 5 percent of the sample size in the same Hospital and necessary modification in the checklist was made based on the nature of gaps identified.The collected data was checked for its completeness, entered using epi-data 3.1 version and exported to SPSS-22 database program for analysis. Frequency distributions of both dependent and independent variables was done and presented by table and texts. To determine associated factors for induction and its outcome, logistic regressions was used. First bi-variate analysis was done to select variables for multivariate analysis and those variables with $p$-value 0.25 or less was interred into multivariate analysis. In multivariable analysis, those variables with $p$-value $<0.05$ will be considered as significantly associated. The model adequacy was checked by using Hosmer and Lemeshow goodness of fit test.

\section{ETHICAL CONSIDERATIONS}

Institutional ethical clearance was first sought from the Institutional Health Research Ethics Review Committee (IHRERC) at Haramaya University, College of Health and Medical Sciences. Next, permission letter was taken from Dire Dawa City administration Health Bureaus and health facility officials. Before the start of data collection informed, voluntary, written and signed consent will be taken from facility head and confidentiality will be maintained and assured.

\section{Results}

\section{Socio-demographic and obstetric Characteristics of the study participant}


Documents of 444 labor induced were reviewed during the study period. The Chart retrieval rate was $100 \%$. From the total participants $341(76.8 \%)$ were in the age group of $20-34$ years with a mean ( \pm SD) of $27( \pm 5)$ years. The minimum and maximum age of mother in years was 16 and 39 . Of the total participants $258(58.1 \%)$ live in rural.

Three hundred fifty five (80\%) of the women were multi para while $89(20 \%)$ were null-para. The study also revealed that $387(87.2 \%)$ of the participants had ANC follow up during pregnancy and the rest $57(12.8 \%)$ had no ANC follow up.326 (73.4\%) of the mother were gestational age of 37-41 weeks followed by gestational of $>42$ weeks $71(16 \%)$.

Before induction time $289(65.1 \%)$ of the women had bishop score 5-8, and the membrane was ruptured in $184(41.4 \%)$ mother. The study also shows that from the total 444 fetuses, 423(95.3) of them had regular fetal heartbeat pattern during induction and $21(4.7 \%)$ had developed none reassuring fetal-heart beat pattern (NRFHRP)after induction.(table 2)

\section{Induction of labor}

\section{Reason and methods for induction of labor}

The three most indications for inducing labor were PROM taking the highest frequency of $179(40.3 \%)$ followed by pregnancy-induced hypertension-160(36\%) and post-term pregnancy 71(16). The methods of induction were either IV oxytocin infusion 212(47.7\%), 169(38.1\%) misoprostol and 63(14.2\%) both.(table 3 )

\section{Outcome of Labor Induction}

Of the 444 women undergoing induction, $73(16.4 \%)$ were delivered by caesarean section while 371 \{83.6\% (95\% Cl: 80-87)\}achieved vaginal delivery. In this study The main aim of induction was to achieve vaginal delivery, all women delivered by caesarean section were considered unsuccessful in labor induction.(figure 1)

\section{Indication for caesarean section}

The main reason for caesarean section was failed induction $28(38 \%)$ followed by fetal distress $19(26 \%)$ and cephalo-pelvic disproportion 14(19\%), malposition and prolonged labor $4(5 \%) \& 8(11)$ respectively. (figure 2)

\section{Associated factors for labor induction outcome}

Associated factors for labor induction outcome during bivariate binary logistic regression.

In bivariate analysis, the following factors Related to labor induction outcome:-resident, post-term, bishop score, method of induction, non-reassuring fetal heart rate pattern, para significant association with success of induction of labor. 
The Mother from rural area had $2.29[\mathrm{COR}=, 95 \% \mathrm{Cl}: 1.37-3.81]$ times more likely to have succeeded in labor induction than those in urban areas. The odds of success of labor induction were $61 \%[\mathrm{COR}=, 95 \%$

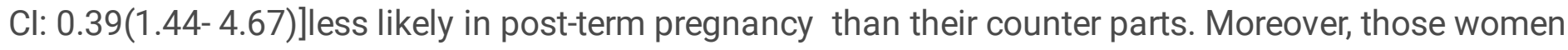
with Bishop scores of 5-8 and $\geq 9$ at admission were 2.5[(COR=,95\% Cl: (1.47-4.26)] times and $1.99[(\mathrm{COR}=, 95 \% \mathrm{Cl}:(0.71-5.60)]$ times more likely induction to be successful compared to those women with $\leq 4$ Bishop Score at admission.

Mothers whose labor is induced using misoprostol were two times[(COR=,95\% Cl: (1.04-4.06] more likely to succeed than oxytocin. In contrast the mother whose labor was induced using both (oxytocin and misoprostol) was $80 \%[($ COR: $0.20(0.1-0.37)]$ less likely to be successful than oxytocin. The odd of success of labor induction was $91 \%[$ (COR:0.081 (0.03-0.20)] less likely in mother with non-reassuring fetal heart rate patterns than their counterparts.Multi-para women were 2.7 [(COR: (1.81-35.80)] times more likely to have a success of labor induction than null-para women. The induction of labor in mothers whose babies weight $>2500 \mathrm{gm}$ were $59 \%$ [(COR: $(0.16-1.07$ ] less likely to be successful than those with $\leq 2500 \mathrm{gm}$. .(table 4)

\section{Associated factors for labor induction outcome during multivariate binary logistic regression.}

In multivariate analysis, being post-term, the induction method and having non-reassuring fetal heart rate pattern have retained their significant association with successful induction. Post-Term mother were $51 \%$ [(AOR: $0.49(0.25-0.98)]$ less likely induction to be successful compared to those women with term pregenacy.

The mother whose labor is induced by misoprostol where 2.5[(AOR: (1.08-5.94] times more likely to succeed in labor induction than those induced by oxytocin. In contrast the mother whose labor is induced by both (oxytocin and misoprostol) was 67\% [(AOR: (0.13-0.86)] less likely to be successful than that labor is induced by oxytocin. The odd of success of labor induction is $90 \%$ [(AOR: $0.10(0.03-0.30)]$ less likely in with non-reassuring fetal heart rate pattern than those of regular fetal heart rate pattern during labor.(table 5)

\section{Discussion}

From 444 card reviewed in this study 73(16.4\%) of them delivered by caesarean section while 371 achieved vaginal delivery making the prevalence rate of success induction $(83.6 \%)$ with $(95 \% \mathrm{Cl}: 80 \%$ $87 \%)$. Post-term, Method of induction, non-reassuring fetal heart rate pattern had a statistically significant Rate of success of induction in St. Luke Catholic Hospital (58\%) and public hospitals of Mekelle town (76\%).(Abdulkadir et al., 2017, Garang Dakjur et al., 2020) This could be because of the difference in quality of induction care provided by the hospitals, skilled professionals and different induction method practice in those setup. (Abdulkadir et al., 2017).Related to the factors associated with the success of induction the study shows that induction of labour occurred mostly in multi Para mother $80 \%$ compared to $20 \%$ in null-para mothers. Even if it does not show the significant of association in multivariate analysis, multi parous mother have two times more likely to have a success of labor induction than null- 
para women. similar finding reported in the study done in Public Hospital in Ethiopia and Dessie Referral Hospital: Northeast Ethiopia (Rade et al., 2018, Dilnessa et al., 2019). increased parity had a favorable bearing on the outcome of induction. Also, labour will proloned in primipara women because cervix was not tested for labour. (Dilnessa et al., 2019).

This study's common indication for labor induction was PROM (40.0\%) followed by post term (16\%).This is in line with the study done in public hospitals of Mekelle town PROM (41\%)followed by post term (19\%) (Garang Lueth, 2020). Contrasting to this the most common indication for labor Induction in Latin America was elective induction (30\%) (Guerra et al., 2009). This difference is because of the two countries socio-economic conditions and PROM was more common in low socioeconomic societies due to wide spread nutrition and infection conditions that would facilitate the condition (Guerra et al., 2009).The study shows that post-term mothers were fifty one percent less likely induction to be successful than those women with term. A similar result was found in the previous study done in Wolliso St. Luke, Catholic Hospital and The Aga Khan University Hospital, Pakistan shows term mother had three and two time more likely to succeed in labor induction than post term mother.(Khan et al., 2012, Abdulkadir et al., 2017) This may be related to when the mothers became post term(Gestational age $>42$ week) there would be respectively big fetus (macrosomia) or decreased placental insufficiency potentially causing fetopelvic disproportion and non-reassurance fetal heart beats, for induction of labor to fail (Abdulkadir et al., 2017).

In this study the most common method of induction was iv infusion of oxytocin (47.7) followed by misoprostol (38.1) This is in line with other study done in Tigray region, Ethiopia $51 \%$ of induction of labour done by oxytocin infusion followed by misoprostol $49 \%$.other Study conducted in Egypt shows $65.5 \%$ of the women received misoprostol while $34.4 \%$ received intravenous oxytocin infusion as a method of labor induction (Abraha, 2020;Abdel Hafiz, 2014 ). Other study done in Latin America where oxytocin IV infusion was used in about $90 \%$ of all labor inductions (Guerra et al., 2009). The choice whether to induce with oxytocin or misoprostol was more on their dependent on the favorability of the woman's cervix and misoprostol availability and protocol used within the unit.(Bekru and Yirdaw, 2018). The mother whose labor is induced by misoprostol where 2.5 times more likely to succeed in labor induction than those induced by oxytocin. ) This is in line with other study done by Coronation Hospital and Universiv of the Witwatersrand, South Africa When compared with oxytocin,misoprostol was more effective for labour induction. The relative risk of failure to achieve vaginal delivery was $0.48(95 \% \mathrm{Cl} 0.35$ to 0.66 ) (Alfirevic, 2006). The mother whose labor is induced by both (oxytocin and misoprostol) was 67\% less likely to be successful than that labor is induced by oxytocin. .(Alfirevic, 2006)

The study also revealed that the presence of non-reassuring fetal heart beat pattern was significantly associated with the success of labor induction. The success of labor induction is ninety percent less likely in with non-reassuring fetal heart rate pattern than those of having regular fetal heart rate pattern. This is consistence with a study done in Wolaita Sodo, South Ethiopia. The success of labor induction is sixty four percent less likely in with non-reassuring fetal heart rate pattern than those of having regular fetal heart rate pattern (Bekru and Yirdaw, 2018). Other study conducted in Wolliso St. Luke, Catholic 
Hospital, South West Shewa, Oromia revealed that Cases who had not fetal heart beat abnormality were five time more likely to be success during induction of labor in contrast with those with abnormality. (Abdulkadir et al., 2017) This could be due to the presence of fetal distress cause non reassuring fetal heart beat pattern and this sign is alarming to take immediate action in order to save the life newborn(Acharya et al., 2017).

\section{Conclusion}

The prevalence rate of success labor induction was found (83.6\%). And the most common indications for labor inductions were PROM and Post term. Furthermore, the study described that the most common method of induction in Dilchora referral Hospital is IV oxytocin infusion. Variables which increased the likelihood of success of labor induction were post term, method of induction and non-reassuring fetal heart rate.

\section{Declarations}

\section{ACKNOWLEDGEMENT}

The authors would like to thank Haramaya University and the administrative bodies and also Our deepest thanks go to dilchora referral hospitals for giving necessary information, data collectors and supervisors

\section{CONFLICT OF INTEREST}

The authors declared no conflict of interest with respect to the research, authorship and publication of this article.

\section{CONTRIBUTION OF AUTHOR (AUTHORSHIP)}

Abel Shiferaw conceived the study under the supervision of Tesfaye Assebe and Melake Demena . Abel Shiferaw wrote the original draft of the manuscript.Abel Shiferaw analyzed data and its interpretation. Tesfaye Assebe and Melake Demena supervised the proposal development, data collection, analysis and the overall work.Tesfaye Assebe and Melake Demena reviewed the draft manuscript for intellectual content and participated in the revision. All authors read and approved the final version of the manuscript.

\section{References}

Abdulkadir, Dejene, A., Geremew, M., \& Dechasa, B. (2017). Induction of labor prevalence and associated factors for its outcome at Wolliso St. Luke. Catholic Hospital, South West Shewa, Oromia. Intern Med, $7(255), 2$.

Acharya, T., Devkota, R., Bhattarai, B., \& Acharya, R. (2017). Outcome of misoprostol and oxytocin in induction of labour. SAGE open medicine, 5, 2050312117700809. 
Al-Shaikh, G., Wahabi, H., Fayed, A., Esmaeil, S., Al-Malki, G., \& Al-Esmaeil, I. (2012). Factors associated with successful induction of labor. Saudi Med J, 33(3), 298-303.

Ayuba, I., Abhulimen, O., \& Ekine, A. (2012). Safety of Induction of Labour in the Niger Delta Region. Greener J Med Sci, 2(6), 173-178.

Bekru, E. T., \& Yirdaw, B. E. (2018). Success of labour induction institution based cross-sectional study Wolaita Sodo, South Ethiopia. International Journal of Nursing and Midwifery.

CSA., C. s. a. (2007). Summary and Statistical report of the 2007 population and housing census.

CSA., C. s. a. (2019). Ethiopia Mini Demographic and Health Survey.

Cunningham, F., Leveno, K., Bloom, S., Hauth, J., Rouse, D., \& Spong, c. (2010). Williams Obstetrics 23rd edition JAMA, 304(4), 474-475.

Dilnessa, T., Temesgen, K., \& Workie, A. (2019). The Proportion of Failed Induction of Labour and Associated Factors among Women Undergoing Induction of Labour in Dessie Referral Hospital: Northeast Ethiopia a Cross-sectional Study. Asian Journal of Pregnancy and Childbirth, 1-13.

Federal Ministry of Health. (2010). Management protocol on selected obstetrics topics

Garang Dakjur, Angesom Kebede, \& Araya Abrha Medhanyie. (2020). Prevalence, outcomes and associated factors of labor induction among women delivered at public hospitals of MEKELLE. BMC pregnacy and childbirth.

Girma, W., TseaduFitsum, \& Wolde, M. (2016). Outcome of Induction and Associated Factors among Term and Post-Term Mothers Managed at Jimma University Specialized Hospital: A Two Years' Retrospective Analysis. Ethiopian journal of health sciences, 26(2), 123-132.

Guerra, G., Cecatti, J., Souza, J., Faúndes, A., Morais, S., Gülmezoglu, A., . . Carroli, G. (2009). Factors and outcomes associated with the induction of labour in Latin America. BJOG: An International Journal of Obstetrics \& Gynaecology, 116(13), 1762-1772.

Khan, N. B., Ahmed, I., Malik, A., \& Sheikh, L. (2012). Factors associated with failed induction of labour in a secondary care hospital. Journal of the Pakistan Medical Association: JPMA, 62(1), 6.

Mekonnen, W., \& Gebremariam, A. (2018). Causes of maternal death in Ethiopia between 1990 and 2016: systematic review with meta-analysis. Ethiopian Journal of Health Development, 32(4).

mohamed $\mathrm{S}$, abdelhafeez $\mathrm{M}, \& \mathrm{~A}, \mathrm{~m}$. (2013). the distance from maternal perineum to fetal headas apredective of successful induction of labour SEMANTIC SCHOLAR.

Morris, J. L., Winikoff, B., Dabash, R., Weeks, A., Faundes, A., Gemzell-Danielsson, K., ... Ho, P. C. (2017). FIGO's updated recommendations for misoprostol used alone in gynecology and obstetrics. 
Organization(WHO)., W. H. (2011). WHO recommendations for induction of labour. World Health Organization.

Pravati, T., Tapasi, P., Prasanna, B., \& Susanta-kumar, M. (2016). prevalence and predictor of faild induction international jornal of pharmaceutical sciences review and research.

Rade, B., Mitku, Y., Weldemicheal, A., Zenebe, Z., \& Desalegn, A. (2018). Induction of Labor and Its Determinant Factors: Retrospective Cross-Sectional Study from a Public Hospital in Ethiopia. J Preg Child Health, 5(388), 2.

SOGC. (2008). guid line for Induction of Labour. National Collabourating Centre for Women's and Children's Health. National Institute for Health and Clinical Excellence.

Sujata, P., Chanania, K., \& Hansa, J. (2017). Comparative Study between Elective Induction of Labour and Spontaneous Labour. Advances in Bioresearch, 8(2).

Sujata., Chanania, K., \& Hansa, J. (2017). Comparative Study between Elective Induction of Labour and Spontaneous Labour. Advances in Bioresearch, 8(2).

Tandu-Umba, B., Tshibangu, R. L., \& Muela, A. M. (2013). Maternal and perinatal outcomes of induction of labor at term in the university clinics of Kinshasa, DR Congo. Open Journal of Obstetrics and Gynecology, 3(01), 154.

Tseyon, T. (2015). Assessment of maternal death and factors affecting maternal death surveillance and response system in Dire Dawa, Ethiopia. (2), 8-9.

Vogel, J., Gülmezoglu, A., Hofmeyr, G., \& Temmerman, M. (2014). Global perspectives on elective induction of labor. Clinical obstetrics and gynecology, 57(2), 331-342.

World health organization. (2018). WHO recommendations: induction of labour at or beyond term.World Health Organization.

\section{Tables}

Table 1:- Sample size calculation by considering different factor that associated with success of labor induction 


\begin{tabular}{|l|l|l|l|l|l|}
\hline Variable & $\begin{array}{l}\text { percentage of } \\
\text { outcome in } \\
\text { unexposed group }\end{array}$ & $\begin{array}{l}\text { percentage of } \\
\text { outcome } \\
\text { exposed group }\end{array}$ & $\begin{array}{l}\text { Sample } \\
\text { size }\end{array}$ & $\begin{array}{l}\text { Sample Size } \\
+10 \% \\
\text { response rate } \\
\text { non- }\end{array}$ & Reference \\
\hline $\begin{array}{l}\text { Gestational } \\
\text { age }\end{array}$ & $47 \%$ & $69 \%$ & 179 & 197 & $\begin{array}{l}\text { (Abdulkadir } \\
\text { et al., } \\
\text { 2017) }\end{array}$ \\
\hline $\begin{array}{l}\text { Mother } \\
\text { Bishop }\end{array}$ & $30 \%$ & $66 \%$ & 84 & 92 & $\begin{array}{l}\text { (Abdulkadir } \\
\text { et al., } \\
\text { 2017) }\end{array}$ \\
\hline $\begin{array}{l}\text { Weight of } \\
\text { new born }\end{array}$ & $47 \%$ & $69 \%$ & 180 & 198 & $\begin{array}{l}\text { (Abdulkadir } \\
\text { et al., } \\
\text { 2017) }\end{array}$ \\
\hline
\end{tabular}

Table 2 Socio demographic and obsetetric Characteristics of Women Who Had undergone induction of labor and Gave Birth In Dilchora Referral Hospital From July 08, 2014 -July 08, 2019 


\begin{tabular}{|c|c|c|}
\hline Variable & Frequency (n) & Percentage (\%) \\
\hline \multicolumn{3}{|l|}{ Age } \\
\hline$<20$ & 55 & 12.4 \\
\hline $20-34$ & 341 & 76.8 \\
\hline$\geq 35$ & 48 & 10.8 \\
\hline \multicolumn{3}{|l|}{ Residence } \\
\hline Urban & 186 & 41.9 \\
\hline Rural & 258 & 58.1 \\
\hline \multicolumn{3}{|l|}{ Parity } \\
\hline Null-para & 89 & 20 \\
\hline Multi-para & 355 & 80 \\
\hline \multicolumn{3}{|l|}{ ANC follow up } \\
\hline Yes & 387 & 87.2 \\
\hline No & 57 & 12.8 \\
\hline \multicolumn{3}{|l|}{ Gestational Age } \\
\hline Less than 36 week & 47 & 10.6 \\
\hline $37-41$ week & 326 & 73.4 \\
\hline$\geq 42$ week & 71 & 16.0 \\
\hline \multicolumn{3}{|l|}{ Membrane status } \\
\hline Intact & 260 & 58.6 \\
\hline Ruptured & 184 & 41.4 \\
\hline \multicolumn{3}{|l|}{ Bishop score } \\
\hline less than/equal to 4 & 122 & 27.5 \\
\hline $5-8$ & 289 & 65.1 \\
\hline greater than/equal to 9 & 33 & 7.4 \\
\hline \multicolumn{3}{|c|}{ NRFHR } \\
\hline yes & 21 & 4.7 \\
\hline No & 423 & 95.3 \\
\hline
\end{tabular}

Table 3 Reason And Methods for Induction of Labor in Women Who had undergone induction of labor and Gave Birth in Dilchora Referral Hospital from July 08, 2014 -July 08, 2019 


\begin{tabular}{clll}
\hline Variable & & Frequency(n) & Percentage (\%) \\
\hline Reason for induction & & & \\
Post term(n=444) & Yes & 71 & 16 \\
& No 373 & 84 \\
Prom(n=444) & Yes 179 & 40 \\
& No 265 & 60 \\
IUFD(n=444) & Yes 33 & 7 \\
& No 411 & 93 \\
Congenital anomaly(n=444) & Yes 21 & 5 \\
& No 423 & 95 \\
Method of induction & & & \\
Iv oxytocin & & & \\
Misoprostol & & 212 & 47.7 \\
Combined & & 169 & 38.1 \\
& & 63 & 14.2 \\
& & &
\end{tabular}

PROM- Premature rupture of membrane. IUFD -Intra uterine fetal death

Table 4 Bivariate Binary Logistic Regression Of Associated Factors For Labor Induction Outcome In Women Delivered In Dilchora Referral Hospital From July 08, 2014 -July 08, 2019 


\begin{tabular}{|c|c|c|c|c|c|c|}
\hline \multirow[t]{2}{*}{ Variable } & \multicolumn{3}{|c|}{ Outcome of Induction } & \multirow{2}{*}{\multicolumn{2}{|c|}{$\operatorname{COR}(95 \%, \mathrm{CI})$}} & \multirow[t]{2}{*}{ P-value } \\
\hline & success & \multicolumn{2}{|l|}{ Un success } & & & \\
\hline \multicolumn{7}{|l|}{ Age } \\
\hline$<20$ & $47(85.5 \%)$ & \multicolumn{2}{|l|}{$8(14.5 \%)$} & \multicolumn{2}{|c|}{$1.17(0.41-3.41)$} & 0.767 \\
\hline $20-34$ & $284(83.3 \%)$ & \multicolumn{2}{|l|}{$57(16.7 \%)$} & \multicolumn{2}{|c|}{$0.99(0.44-2.24)$} & 0.993 \\
\hline$\geq 35$ & $40(83.3 \%)$ & \multicolumn{2}{|l|}{$8(16.7 \%)$} & \multicolumn{2}{|l|}{1} & \\
\hline \multicolumn{7}{|c|}{ Residential Address } \\
\hline Rural & $228(88 \%)$ & \multicolumn{2}{|l|}{$30(12 \%)$} & \multicolumn{2}{|c|}{$2.29(1.37-3.81)$} & $0.002 *$ \\
\hline Urban & $143(77 \%)$ & \multicolumn{2}{|l|}{$43(23 \%)$} & \multicolumn{2}{|c|}{1.00} & \\
\hline \multicolumn{7}{|l|}{ Post-term } \\
\hline Yes & $50(70 \%)$ & \multicolumn{2}{|l|}{$21(30 \%)$} & \multicolumn{2}{|c|}{$0.39(0.21-0.69)$} & $0.001 *$ \\
\hline No & $321(86 \%)$ & \multicolumn{2}{|l|}{$52(14 \%)$} & \multicolumn{2}{|c|}{1.00} & \\
\hline \multicolumn{7}{|l|}{ Bishop score } \\
\hline $5-8$ & $253(88 \%)$ & \multicolumn{2}{|l|}{$36(12 \%)$} & \multicolumn{2}{|c|}{$2.50(1.47-4.26)$} & $0.001 *$ \\
\hline$>9$ & $28(85 \%)$ & \multicolumn{2}{|l|}{$5(15 \%)$} & \multicolumn{2}{|c|}{$1.99(0.71-5.60)$} & 0.192 \\
\hline$\leq 4$ & $90(74 \%)$ & \multicolumn{2}{|l|}{$32(26 \%)$} & \multicolumn{2}{|l|}{1.00} & \\
\hline \multicolumn{7}{|c|}{ Method of induction } \\
\hline Misoprostol & $156(92 \%)$ & $13(8 \%)$ & & \multicolumn{3}{|c|}{\begin{tabular}{l|l}
$.05(1.04-4.06)$ & $0.038^{*}$
\end{tabular}} \\
\hline Combined & $34(54 \%)$ & $29(46 \%)$ & & $0(0.14-0.37)$ & $0.001^{*}$ & \\
\hline Oxytocin & $181(85 \%)$ & $31(15 \%)$ & & & & \\
\hline NRFHRP & & & & & & \\
\hline Yes & $7(33 \%)$ & $14(67 \%)$ & & $3(0.03-0.21)$ & $0.001^{*}$ & \\
\hline No & $364(86 \%)$ & $59(14 \%)$ & & & & \\
\hline Para & & & & & & \\
\hline Multi Para & $308(86.6)$ & $47(13.4 \%)$ & & $2.7(1.56-4.8$ & & $0.001 *$ \\
\hline Null Para & $63(70.8)$ & $26(29.2 \%)$ & & 1.00 & & \\
\hline New born weigh & & & & & & \\
\hline$>2500 \mathrm{gm}$ & $315(82 \%)$ & $68(18 \%)$ & & $0.41(0.16-1$ & 57) & $0.069 *$ \\
\hline$\leq 2500 \mathrm{gm}$ & $56(92 \%)$ & $5(8 \%)$ & & 1.00 & & \\
\hline
\end{tabular}

*- statistically siginificant at $P$-value $<0.25$

IUFD-intrauterine fetal death,

NRFHRP-Non reassuring fetal heart rate pattern

Table 5 Multivariate Binary Logistic Regression Of Associated Factors For Labor Induction Outcome In Women Delivered In Dilchora Referral Hospital From July 08, 2014 -July 08, 2019 


\begin{tabular}{|c|c|c|}
\hline Variable & AOR(95\%,CI) & P-value \\
\hline \multicolumn{3}{|c|}{ Residential Address } \\
\hline Rural & $1.68(0.91-3.10)$ & 0.095 \\
\hline Urban & 1.00 & \\
\hline \multicolumn{3}{|l|}{ post term } \\
\hline Yes & $0.49(0.25-0.98)$ & $0.044^{* *}$ \\
\hline No & 1.00 & \\
\hline \multicolumn{3}{|l|}{ Bishop score } \\
\hline $5-8$ & $2.07(0.90-4.76)$ & 0.086 \\
\hline$\geq 9$ & $1.53(0.40-5.82)$ & 0.533 \\
\hline$\leq 4$ & 1.00 & \\
\hline \multicolumn{3}{|c|}{ Method of induction } \\
\hline Oxytocin & 1.00 & \\
\hline Misoprostol & $2.53(1.08-5.94)$ & $0.033^{* *}$ \\
\hline Combined & $0.33(0.13-0.86)$ & $0.022^{* *}$ \\
\hline \multicolumn{3}{|l|}{ NRFHP } \\
\hline Yes & $0.10(0.03-0.30)$ & $0.001^{* *}$ \\
\hline No & 1.00 & \\
\hline \multicolumn{3}{|l|}{ Para } \\
\hline Multi Para & $1.7(0.94-3.47)$ & 0.73 \\
\hline Null Para & 1.00 & \\
\hline \multicolumn{3}{|l|}{ New born weight } \\
\hline$>2500 \mathrm{gm}$ & $0.39(0.13-1.15)$ & 0.088 \\
\hline$\leq 2500 \mathrm{gm}$ & 1.00 & \\
\hline
\end{tabular}

**- statistically significant at P-Value $\leq 0.05$

IUFD- intrauterine fetal death

NRFHRP- Non reassuring fetal heart rate pattern 


\section{Figures}

\section{Outcome of labor Induction}

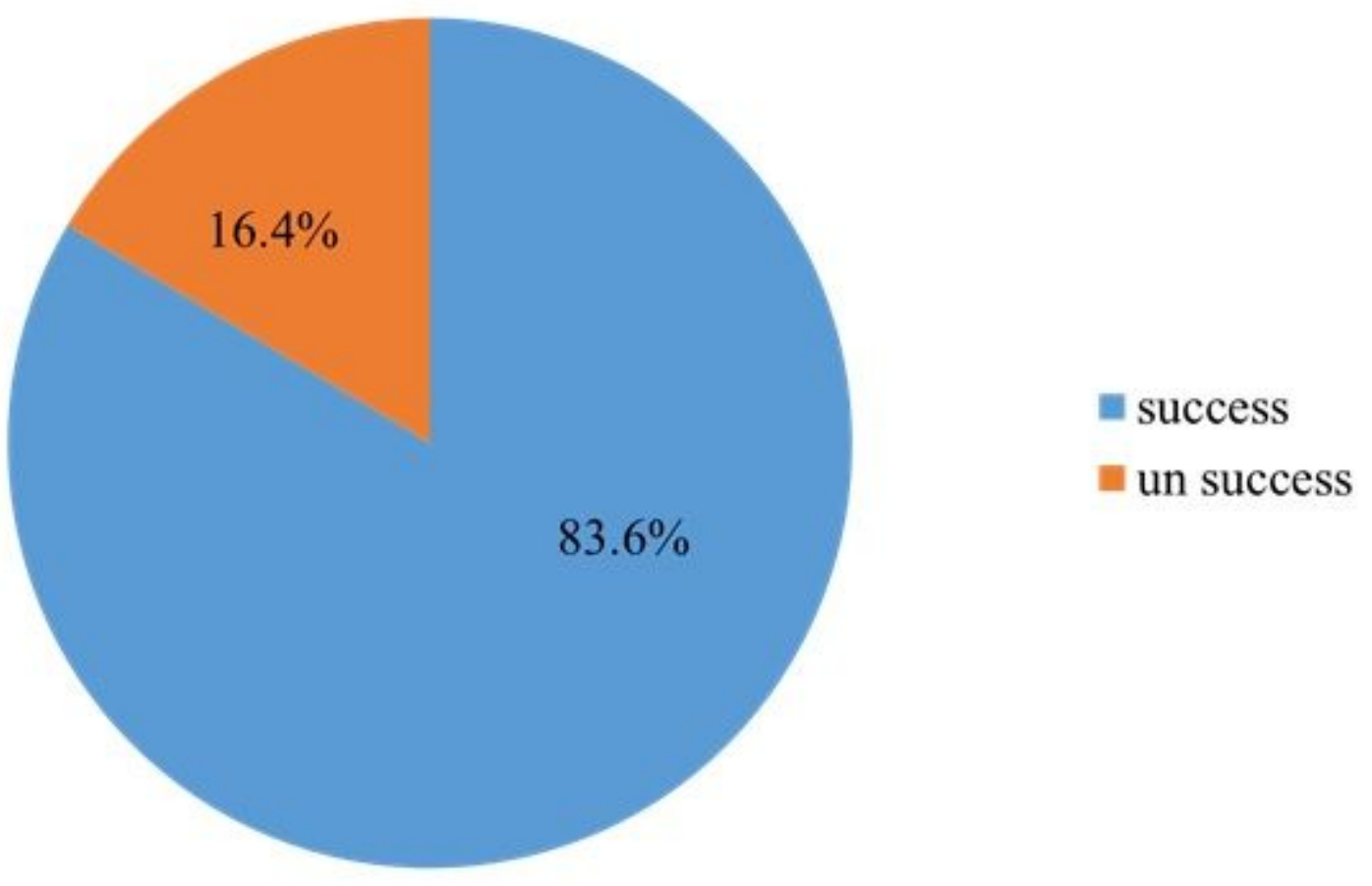

Figure 1

Outcome Of Labor Induction among Women Who Had undergone induction of labor and Gave Birth In Dilchora Referral Hospital From July 08, 2014 - July 08, 2019

\section{Indication for CS}

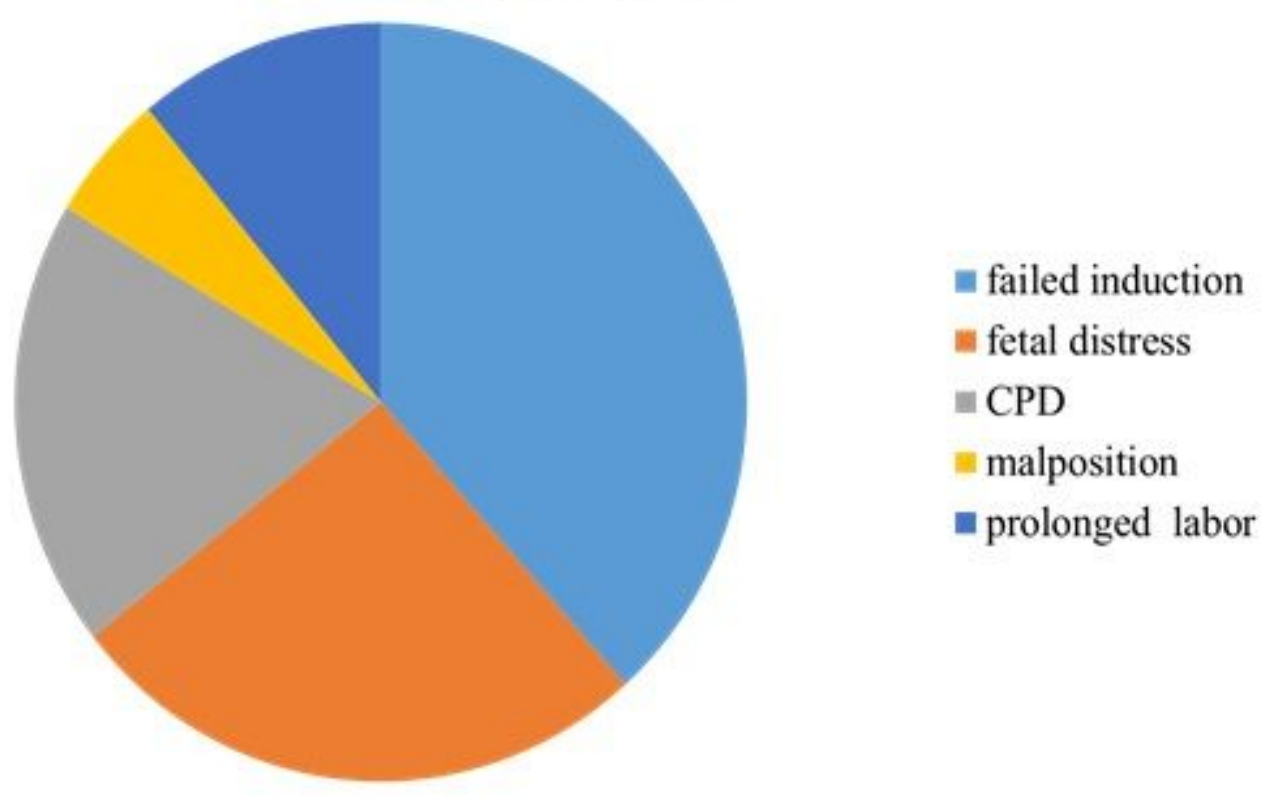

Figure 2 
Indication for CS among Women Who had undergone induction of labor and Gave Birth in Dilchora Referral Hospital from July 08, 2014 -July 08, 2019

\section{Supplementary Files}

This is a list of supplementary files associated with this preprint. Click to download.

- Appendix.docx 